\title{
Socialização feminina, protagonismo humano e educação: uma análise a partir de Christine de Pizan
}

\section{Female socialization, human protagonism and education: an analysis from Christine de Pizan \\ Socialización femenina, protagonismo humano y educación: un análisis a partir de Christine de Pizan}

\author{
Patrícia Ketzer* \\ Ana Paula Scheffer ${ }^{* *}$
}

\section{Resumo}

Christine de Pizan (1364-1430) defendeu uma educação de qualidade como ferramenta potencial para impulsionar o protagonismo humano, além de promover a igualdade. Afirmava a necessidade de se educar meninos e meninas igualmente, no processo de socialização, de modo a possibilitar o desenvolvimento intelectual das mulheres. Com o objetivo de investigar quais os principais pontos defendidos por Christine de Pizan em prol de uma educação igualitária, realizou-se uma pesquisa bibliográfica, buscando discorrer sobre a importância da educação igualitária no protagonismo humano. $\mathrm{O}$ artigo em questão foi estruturado em duas etapas: em um primeiro momento, discorre-se sobre quem foi Christine de Pizan e em que contexto ela estava inserida. Em um segundo momento, objetiva-se analisar a contribuição de Pizan para a Educação, bem como compreender a visão da autora acerca da temática, relacionando-a com o contexto educacional atual. Como considerações finais, destaca-se a educação como cerne estruturante no protagonismo humano, em conjunto com o seu potencial libertador.

Palavras-chave: Christine de Pizan; educação; socialização feminina; protagonismo; igualdade.

\section{Abstract}

Christine de Pizan (1364-1430) has advocated for education as a potential tool for the advancement of human protagonism and equality. According to Pizan, during the socialization process, there is a necessity to equintaually educate girls and boys to enhance women's intellectual capabilities. In order to investigate which are the main points defended by Christine de Pizan in favor of an egalitarian education, a bibliographic research was carried out, seeking to discuss the importance of egalitarian education in human protagonism. This article was

Recebido: 27/07/2020 - Aprovado: 21/05/2021

http://dx.doi.org/10.5335/rep.v28i1.11405

Graduação e mestrado em Filosofia pela Universidade Federal de Santa Maria e doutorado em Filosofia pela Pontifícia Universidade Católica do Rio Grande do Sul. Atualmente é professora da Universidade de Passo Fundo. Tem experiência na área de Filosofia, com ênfase em Epistemologia, atuando principalmente nos seguintes temas: injustiças epistêmicas, epistemologia feminista, questões de gênero. Orcid: https://orcid.org/0000-0001-9742-0076. E-mail: patriciaketzer@gmail.com

* Graduada em Arquitetura e Urbanismo e em filosofia pela Universidade de Passo Fundo; mestre em Engenharia Civil e Ambiental pela Universidade de Passo Fundo. Tem experiência na área de Arquitetura e Urbanismo, atuando principalmente nos seguintes temas: sustentabilidade, arquitetura, meio ambiente, mobilidade sustentável e infraestrutura. Orcid: https://orcid.org/0000-0002-5146-7853. E-mail: 119642@upf.br 
structured in two stages: first, Christine de Pizan was presented in its social and historical context; afterward, Pizan's contribution to education was explained, analyzed and, finally, paralleled with today's educational practice. The final considerations highlighted is that education constitutes an indispensable foundation for human protagonism and human autonomy.

Keywords: Christine de Pizan; education; female socialization; protagonism; equality.

\title{
Resumen
}

\begin{abstract}
Christine de Pizan (1364-1430) defendió la educación de calidad como una herramienta potencial para impulsar el protagonismo humano, además de promover la igualdad. Afirmó la necesidad de educar a los niños y niñas por igual, en el proceso de socialización, para permitir el desarrollo intelectual de las mujeres. Con el fin de indagar los principales puntos defendidos por Christine de Pizan a favor de una educación igualitaria, se realizó una investigación bibliográfica, buscando discutir la importancia de la educación igualitaria en el protagonismo humano. El artículo en cuestión se estructuró en dos etapas: al principio, se discute quién era Christine de Pizan y en qué contexto se insertó. En un segundo paso, el objetivo es analizar la contribución de Pizan a la educación, así como comprender la posición de la autora sobre el tema, relacionándolo con el contexto educativo actual. Como consideraciones finales, se destaca la educación como un núcleo estructurante en el protagonismo humano, junto con su potencial liberador.
\end{abstract}

Palabras clave: Christine de Pizan; educación; socialización femenina; protagonismo; igualdad.

\section{Introdução}

Educação de qualidade é um dos 17 objetivos do desenvolvimento sustentável promovidos pela Organização das Nações Unidas (ONU) em prol de um mundo mais justo e fraterno. Mais especificamente, o objetivo número 4 preconiza "assegurar a educação inclusiva e equitativa de qualidade, e promover oportunidades de aprendizagem ao longo da vida para todos" (ONU, 2015, não paginado). Para tanto, uma série de metas são estabelecidas dentre elas: eliminar as disparidades de gênero e garantir a igualdade de acesso a todos os níveis de educação. Em pleno século XXI, apesar dos enormes desafios para a efetivação desse objetivo, deve-se destacar o reconhecimento e a busca por educação de qualidade em prol do protagonismo humano e da igualdade, panorama que nem sempre se apresentou de tal perspectiva.

Christine de Pizan, uma mulher escritora do período Medieval, projetou para além de seu tempo uma visão igualitária principalmente no âmbito da questão de gênero e da educação. Discorre a respeito de inúmeros temas que mexem com o imaginário humano, ajustando a realidade para um cenário ideal e, a partir disso, fazendo refletir e repensar os dogmas sociais impostos no período.

A luta iniciada por Christine de Pizan, na defesa de educação igualitária para ambos os sexos, não finda em nossa sociedade contemporânea. Teóricas feministas 
têm reforçado a necessidade tanto de um processo de socialização quanto de uma educação que contemple igualmente meninos e meninas, desenvolvendo as potencialidades de ambos. Ao invés disso, o que se constata ainda hoje é uma educação que reforça os ideais da sociedade heteropatriarcal capitalista de supremacia branca em que vivemos.

Deste modo, este artigo se propõe a investigar quais os principais pontos defendidos por Christine de Pizan em prol de uma educação igualitária, além de discorrer sobre a sua importância no protagonismo humano. Para cumprir tal objetivo, o artigo foi estruturado em duas etapas, a saber: em um primeiro momento, visa-se compreender a respeito da biografia da autora e o contexto de sua existência, que possibilitou o desenvolvimento de sua obra. Em um segundo momento, busca-se identificar sua contribuição para a educação, explicitando as dificuldades contemporâneas de sua efetivação, que se dão em função de preconceitos e visões distorcidas acerca do gênero. Para, por fim, oferecer uma alternativa, baseada na noção de educação como prática da liberdade, que promove verdadeiramente o protagonismo humano.

\section{Para além do seu tempo: Christine de Pizan}

Em geral, a capacidade intelectual feminina foi menosprezada, sendo as mulheres escamoteadas da História da Filosofia e, em função disso, há informações desencontradas e confusas acerca dessa filósofa de tamanha monta do período Medieval. Além disso, conceitos epistemológicos foram construídos a partir de estereótipos de masculinidade, como o conceito de razão e de objetividade (LLOYD, G., 1984; LLOYD, E. 1995; ROONEY, 1991), o que as excluiu da produção do saber científico e filosófico.

Esses conceitos servem a uma dupla função: epistemológica e política (LONGINO, 2012, p. 511), pois influenciam diretamente todo o ideal de cientificidade, que é pautado em cima de ambos. Conceitos centrais que pautaram as discussões sobre o conhecimento e a ciência foram construídos com base em estereótipos de gênero. Apesar disso, Christine de Pizan e sua obra chegaram até nós, mesmo com as tentativas de apagamento. Por meio do presente trabalho, também se possibilita o resgate de sua biografia, de sua história e de seu pensamento.

Escritora do período Medieval, Christine de Pizan obteve destaque pelo seu grau de protagonismo e posicionamento crítico no que tange o campo da concepção feminina, suas atribuições e, principalmente, ao discorrer a respeito da influência 
que a educação possuía na condição social da mulher. Nasceu em Veneza em 1364, filha de Thomas de Pizan; sobre sua mãe não há relatos (LEITE, 2008). Calado (2006, p. 03) e Karawejczyk (2017, p. 190) atribuem a função do pai como astrólogo, Leite (2008, p. 12) descreve a profissão de Thomas como Professor da Universidade de Bolonha, ao passo que Cardoso (2017, p. 135) o caracteriza como astrólogo e médico.

Em 1368, sua família passa a residir em Paris a convite da corte do Rei Charles V, que solicita os serviços de Thomas de Pizan. Tal mudança favoreceu a educação de Christine, que se situava em uma esfera promissora, possuindo também acesso à biblioteca real. Ao completar quinze anos (1379), seu pai escolhe Etienne Castel, futuro secretário do rei, para ser marido de Pizan (LEITE, 2018).

Segundo Leite (2008) a década de oitenta foi um período conturbando para a França em função do falecimento do rei, ao passo que para Christine, representou a perda de seu pai em 1386, e de seu marido três anos depois. Pizan assume a responsabilidade sobre seus três filhos, além de auxiliar nos cuidados de sua mãe. "Nesse momento de desespero, ela encontra refúgio nos estudos para suas aflições" (LEITE, 2008, p. 12).

O conhecimento e as informações passaram a circular com maior frequência no período em que Christine viveu, atribuindo às mulheres mais espaço e poder. Ao contrário do imaginário popular, durante os primeiros séculos da Idade Média, as mulheres gozavam de alguns direitos, garantidos pela lei e pelos costumes. Podiam exercer praticamente todas as profissões, tinham direito de propriedade e de sucessão. Havia, inclusive, mulheres que atuavam politicamente, participando de assembleias, com direito ao voto (ALVES; PITANGUY, 2017).

Devido a constantes guerras, longas viagens e recolhimento aos monastérios por parte dos homens, as mulheres tornaram-se a maioria da população adulta, assumindo os negócios da família. Deste modo, fazia-se necessário que entendessem de contabilidade e legislação, para realizarem as transações comerciais e se defenderem em juízo. Um olhar histórico nos possibilita a constatação de que a participação da mulher na esfera pública esteve, frequentemente, ligada ao afastamento do homem por motivo de guerras (ALVES; PITANGUY, 2017).

Nas primeiras décadas da Idade Média se têm registros de mulheres exercendo tarefas ditas masculinas, como a serralheria e a carpintaria, ainda que se concentrassem majoritariamente em profissões femininas como tecelagem, costura e bordados. Participavam do comércio, juntamente com os seus maridos e, após a sua morte assumiam os negócios. Entretanto, a indústria doméstica, ligada às mulhe- 
res, costumava ser a principal fonte de renda ou uma complementação necessária para o orçamento familiar. Podendo exercer o direito de sucessão, não era incomum uma herdeira gerir sua própria renda, mesmo casada (ALVES; PITANGUY, 2017).

A despeito desse contexto relativamente favorável, a ascensão do trabalho feminino provou a oposição dos trabalhadores homens, pois a competição rebaixava 0 nível salarial geral. Em função disso, surgiram restrições à participação da mulher no mercado de trabalho, como em Londres, no ano de 1344, quando a organização de alfaiates proibiu seus membros de empregarem mulheres que não fossem suas esposas ou filhas (ALVES; PITANGUY, 2017).

Apesar da participação da mulher na vida social e econômica da Idade Média, a concepção que foi disseminada era a de uma mulher frágil e apática, entretida em seus bordados, à espera do cavalheiro. Segundo Alves e Pitanguy (2017), essa imagem exclui a grande massa de mulheres da representação simbólica, além de refletir uma visão distorcida do que seria seu cotidiano nesse período. Trata-se de uma defasagem entre a posição concreta da mulher em sua vida diária e a representação simbólica que se tinha dela.

É nesse contexto que Christine de Pizan, após perder o marido e o pai, decide se tornar escritora. Em um primeiro momento, começa a escrever poesias participando de concursos. A boa recepção de seus textos lhe indicara o caminho para seguir na profissão. Segundo Leite (2018), uma boa parcela de seu público se interessava em saber a respeito do conteúdo abordado por uma mulher, ao passo que a outra parcela lia por admiração à escritora e aos seus temas. Christine escreveu em torno de quinze obras.

Segundo Karawejczyk (2017, p. 197), Christine inovou ao concentrar sua atenção em mulheres de diversos níveis sociais "mulheres que viviam ao lado de reis, de nobres, de mercadores, artesãos e trabalhadores, que trabalhavam dentro e fora das paredes domésticas, podendo ser cultas ou iletradas, humildes ou poderosas, ricas ou pobres". Entre os inúmeros temas: mitologia, tratados de moral, educação, política e ética, um deles se destaca até hoje por sua originalidade: a questão do feminino (LEITE, 2018). Pizan defendia que a desigualdade entre homens e mulheres é derivada do processo de socialização, alegando que se as mulheres tivessem acesso à educação teriam papéis tão importantes e úteis para a sociedade quanto os homens (LEITE, 2018).

É dentro desse cenário que Pizan apresenta percepções contrárias a visão e os costumes recorrentes na época e faz da educação sua aliada. Torna-se a primeira mulher a ser indicada à poeta oficial da corte. Muitas a consideram uma das pri- 
meiras feministas, visto que possuía um discurso conscientemente articulado em defesa dos direitos da mulher.

Entrou em polêmicas com escritores de renome da época, defendendo a igualdade entre os sexos. Um deles foi Jean de Meung, que escreveu a segunda parte de o Romance da Rosa. Pizan o critica por seu tom misógino, dando origem a primeira disputa escrita da literatura francesa.

A autora afirmou a urgência em fornecer às meninas uma educação idêntica à dos meninos, defendendo que se fosse costume as mandar à escola e as ensinar ciências, elas aprenderiam da mesma forma que os meninos e compreenderiam as sutilezas das artes e ciências (ALVES; PITANGUY, 2017). Em 1422, Pizan vive os últimos momentos de sua vida no mosteiro de Poissy, onde vem a falecer em 1430 com 66 anos (CARDOSO, 2017).

\section{0 processo de socialização feminino e o protagonismo humano por meio da educação}

No século XII, os teóricos começam a olhar para a educação analisando o comportamento das crianças e das mulheres que passam a ser analisadas como inconstantes, o que faz com que seu comportamento necessite ser regulado. É a partir do Concílio de Latrão, de 1179, que todas as igrejas passam a ser obrigadas a manter uma escola, que ensine aritmética, geometria, gramática, música e teologia. Também se podia contar com a boa vontade dos Senhores Feudais, caso tivessem o interesse de fundar uma escola, ou com a união de um grupo de habitantes que resolvesse se associar e pagar um professor para ensinar aos seus filhos.

Era por volta dos sete ou oito anos que as crianças começavam a frequentar a escola, os estudos seguiam-se por dez anos, até adentrarem a universidade. O acesso a livros era raro, o que contribuiu para que predominasse a cultura da oralidade. O professor lia e comentava os autores clássicos para os alunos, os quais debatiam com o mestre. Esse método estimulou a memorização e o debate em todos os níveis de ensino (LEITE, 2008).

Entre sete e oito anos as crianças ainda podiam brincar juntas, ainda que sempre sob vigilância. Posteriormente, a educação de meninos e meninas passava a diferir, destacando-se as diferenças nos processos de socialização entre os gêneros. Havia também, certamente, uma diferença significativa entre a educação dos nobres e camponeses. Aos cinco anos, os nobres já sabiam montar, praticavam jogos 
voltados para formação do cavaleiro, e tinham aprendizados específicos, na escola ou em casa com um preceptor. A esse preceptor era destinada a tarefa de socializar o jovem, ensinando-o a falar adequadamente, a ter boas maneiras, ser um bom anfitrião, e conhecer diferentes livros. Leite (2008) destaca o fato de se tratar de uma educação utilitária, pois tinha uso específico na vida do pequeno nobre.

Enquanto isso, os filhos de camponeses não frequentavam a escola, cabendo aos pais os ensinar sua profissão, enquanto a mãe lhes ensinava os elementos da fé cristã. "A mãe era responsável pela formação moral e social. Os contos épicos e histórias diversas conduziam o jovem à resignação, à honra e à coragem" (LEITE, 2008, p. 174). Outro espaço de aprendizagem possível eram os conventos. Havia conventos para meninos e outros para meninas, mas também haviam espaços mistos nos primeiros anos de ensino.

Em relação à educação das meninas, a maioria dos teóricos defendia que deveria voltar-se para o conhecimento prático. A camponesa deveria desenvolver a capacidade de cuidar do lar, enquanto a burguesa e a nobre deveriam ter uma cultura um pouco mais aprimorada, que lhes possibilitasse comandar os empregados e empregadas. Também deviam saber ler e escrever de acordo com suas responsabilidades sociais. Em comum, havia a necessidade de que soubessem costurar, fiar, tecer e bordar. A educação de toda menina deveria ser orientada, principalmente, para o casamento, o cuidado da casa, dos maridos e dos filhos (LEITE, 2008).

Vincent de Beauvais, no século XIII, destina um capítulo de seu livro de vinte e um capítulos às mulheres. Nesse capítulo, destaca sua preocupação com a castidade feminina, e defende que as mulheres deviam aprender a ler para acessar os preceitos morais e assim evitar maus pensamentos. Note-se que a educação feminina era voltada para a formação de um caráter dócil, que servia para controlar seu maior bem: a virgindade. Caberia aos pais dar os ensinamentos necessários para que a mulher "cumprisse" com os deveres sexuais adequadamente depois do casamento. Leite (2008, p. 177) destaca ainda que:

Quanto à vida de casada, indica que a mulher devia suportar os defeitos do marido, evitar o ciúme, não usar ornamentos, pintura etc. Pode-se perceber que a formação feminina não objetivava a exaltação do espírito intelectual da mulher, e sim sua adequação aos moldes estipulados pelos homens.

É nesse contexto que Christine de Pizan se torna uma escritora que questiona o lugar social atribuído à mulher. Uma das obras de relevância de Pizan é La cité de dames, escrita em 1405, e traduzida no Brasil por Luciana Eleonora de Freitas Calado, em 2006, como A Cidade das Damas. Nessa obra, a autora idealiza uma 
cidade de mulheres, na qual desenvolve histórias da vida feminina que, por meio de seu progresso intelectual, conseguiram ocupar espaços na esfera pública. Pizan buscou explicitar as capacidades intelectuais das mulheres, sem deixar de considerar que a condição à qual estavam submetidas as afastava do conhecimento. Defendeu abertamente que os assuntos que dizem respeito à vida social também deveriam ser debatidos pelas mulheres.

Em A Cidade das Damas, Pizan faz uso de alegorias para revelar a estratégia narrativa de luta das mulheres medievais contra os ataques misóginos que sofriam. As Damas alegóricas Razão, Retidão e Justiça são apresentadas de modo a desarticular o discurso misógino. As Damas assumem o posicionamento em prol da condição feminina dando voz às mulheres e valorizando o feminino. Assim, possibilitando a conscientização das mulheres enquanto agentes de seu próprio destino. A verdade era uma perspectiva masculina, possível somente aos homens, visto que acessada pelo poder da escrita, desse modo reforçava a misoginia e impunha às mulheres os ditames sociais da fragilidade de sua condição (SILVA, 2016).

O diálogo narrado entre as três Damas e a narradora-personagem ocorre conjuntamente com a construção da Cidade, que simboliza um espaço de proteção a elas. A defesa do feminino, em Pizan, reivindica a igualdade entre os sexos na busca de direitos e oportunidades iguais para todos. Pizan defende o direito à educação, ao conhecimento, à vida pública. "Em suma, o direito de ser mulher; favorecendo-as no que diz respeito à formação humanística e à participação ativa na sociedade" (SILVA, 2016, p. 36).

Segundo Leite (2018), pode-se destacar como ideias principais do livro III da Cidade das Damas, que: 1) a diferença entre homens e mulheres é de origem social porque as mulheres não têm acesso à educação; 2) deve-se mudar a ideia de que só o homem é o detentor da palavra; 3) provam-se a dignidade e a utilidade da mulher para a sociedade.

Já Calado (2006) considera que, para Pizan, a educação vai além do saber adquirido designado à própria formação e ao aprimoramento e se integra ao social, tendo um papel de condutora e intermediária do saber. Em sua obra Cidade das Damas, o enfoque central se constitui na "busca das relações de gênero ao longo dos tempos, por meio do resgate da memória feminina, esquecida pela história" (CALADO, 2006, p. 83), redefinindo alguns mitos constituintes de uma imagem deformadora do feminino, como por exemplo, o mito da origem, do pecado original (CALADO, 2006). 
Ainda, em Cidade das Damas, Pizan incita seus leitores e leitoras a "resolver suas questões, baseando, não apenas pelas leituras dos livros, mas também pela leitura de mundo, ou seja, por sua própria experiência, seu saber empírico, obtendo seus próprios julgamentos" (CALADO, 2006, p. 92). Além disso, a autora enfatiza que Pizan, por meio da alegoria criada na Cidade das Damas, ensina a não acreditar em um saber absoluto de parte das grandes autoridades, uma vez que a falha e o erro fazem parte do humano.

Percebes que mesmo os maiores filósofos, aqueles que tu invocas contra teu próprio sexo, não conseguiram distinguir o certo do errado, e se contradizem e se criticam uns aos outros sem cessar, como tu mesma viste em Metafísica de Aristóteles, no qual ele critica e refuta igualmente as opiniões de Platão e de outros filósofos citando-os. E presta atenção ainda que Santo Agostinho e outros doutores da Igreja fizeram o mesmo em certas passagens de Aristóteles, considerando o Príncipe dos filósofos, e a quem devemo-lo as mais altas doutrinas da filosofia natural e moral (PIZAN apud CALADO, 2006, p. 92).

O protagonismo da educação é enfatizado em conjunto com diferentes olhares diante do papel feminino: "se fosse costume enviar as mocinhas à escola e ensiná-las metodicamente as ciências, como é feito para os rapazes, elas aprenderiam e compreenderiam as dificuldades de todas as artes e de todas as ciências tão bem quanto eles" (PIZAN apud KARAWEJCZYK, 2017, p. 195). Cristine de Pizan também evidencia uma nova visão do feminino, reivindicando uma mudança de olhar sobre a mulher para além da posição de sedutora. Segundo Leite (2018, p. 118),

[...] essa divisão singular proposta por Christine propõe uma nova forma de ver a mulher não mais sob o critério religioso da castidade, mas como um ser humano com um papel a ser cumprido e respeitado na sociedade tanto na esfera privada como na pública. A mulher deixa de ser vista somente a partir de sua função biológica para assumir uma atividade social.

A defesa dessa concepção igualitária perpassa séculos de lutas e ainda permanece, em pleno século XXI, no qual o preconceito e a desigualdade ainda são temas recorrentes que necessitam da educação como antídoto. Tal é a necessidade de alcançarmos igualdade de gênero que a ONU estipulou como o objetivo cinco, dos dezessete objetivos do desenvolvimento sustentável. Segundo a ONU (2015), é preciso:

5. Alcançar a igualdade de gênero e empoderar todas as mulheres e meninas. 5.1 Acabar com todas as formas de discriminação contra todas as mulheres e meninas em toda parte; 5.2 Eliminar todas as formas de violência contra todas as mulheres e meninas nas esferas públicas e privadas, incluindo o tráfico e exploração sexual e de outros tipos; 5.3 Eliminar todas as práticas nocivas, como os casamentos prematuros, forçados e de crianças e mutilações genitais femininas; 5.4 Reconhecer e valorizar o trabalho de assistência e doméstico não remunerado, por meio da disponibilização de serviços públicos, infraestrutura 
e políticas de proteção social, bem como a promoção da responsabilidade compartilhada dentro do lar e da família, conforme os contextos nacionais; 5.5 Garantir a participação plena e efetiva das mulheres e a igualdade de oportunidades para a liderança em todos os níveis de tomada de decisão na vida política, econômica e pública; 5.6 Assegurar o acesso universal à saúde sexual e reprodutiva e os direitos reprodutivos, como acordado em conformidade com o Programa de Ação da Conferência Internacional sobre População e Desenvolvimento e com a Plataforma de Ação de Pequim e os documentos resultantes de suas conferências de revisão; 5.a Realizar reformas para dar às mulheres direitos iguais aos recursos econômicos, bem como o acesso a propriedade e controle sobre a terra e outras formas de propriedade, serviços financeiros, herança e os recursos naturais, de acordo com as leis nacionais 5.b Aumentar o uso de tecnologias de base, em particular as tecnologias de informação e comunicação, para promover o empoderamento das mulheres; 5.c Adotar e fortalecer políticas sólidas e legislação aplicável para a promoção da igualdade de gênero e o empoderamento de todas as mulheres e meninas em todos os níveis.

Nota-se que a luta iniciada, talvez ainda antes de Pizan, não chegou ao fim. As teóricas feministas do século XXI seguem afirmando a necessidade destacada por Christine de Pizan, no século XIV e XV, de se oportunizar espaços de socialização e educação igualitários para meninas e meninos. Em 1949, quando escreve a primeira edição de seu mais famoso livro, O Segundo Sexo, Simone de Beauvoir (2009, p. 267) afirma que "ninguém nasce mulher: torna-se mulher". Para Beauvoir, existe um "fazer-se mulher", a partir de normas e valores socioculturais que são ensinados e reiterados nos gestos, comportamentos e preferências. Ela completa "nenhum destino biológico, psíquico, econômico define a forma que a fêmea humana assume no seio da sociedade; é o conjunto da civilização que elabora esse produto intermediário entre o macho e o castrado que qualificam o feminino" (BEAUVOIR, 2009, p. 267).

O ser mulher, ou ainda, os papéis que cabem a mulher, são determinados socialmente e culturalmente, não sendo algo adquirido pelo biológico, como defendem abordagens mais tradicionais da psicologia, religião, medicina e filosofia. Existem inúmeras dimensões que põem em xeque a visão reducionista de que ser mulher ou homem depende estritamente do sexo biológico.

Louro (2008, p. 18) afirma que "não é o momento do nascimento e da nomeação de um corpo como macho ou fêmea que faz deste um sujeito masculino ou feminino", mas a construção do gênero ocorre ao longo de toda vida. Uma argumentação desta ordem exige se colocar contra a naturalização do feminino e do masculino, constituindo-se como desafio perante uma tradição cultural fortemente fixista e estereotipada.

Vianna e Finco (2009, p. 268) em sua pesquisa referente às relações de gênero e poder presentes nos processos de socialização de crianças pequenas, na educação infantil, questionam: 
Refletir sobre os fundamentos dessas afirmações no âmbito da educação e, mais especificamente, da educação infantil exige o questionamento de suas origens e do peso do caráter biológico na construção das diferenças. Isso pressupõe, por exemplo, indagar a respeito da interferência e do papel da cultura nos processos de socialização e de formação de meninas e meninos desde suas primeiras experiências de vida na instituição escolar.

Mas, de onde vem as orientações e ensinamentos de como devem se comportar os gêneros masculino e feminino? São os especialistas de diversas áreas que dizem o que deve ser vestido, comido, conquistado, como se apresentar para conseguir emprego, como ser aceito socialmente. As diferentes agências de socialização, representadas pela família, pela mídia, pela igreja, determinam nosso ser e estar no mundo. A ciência também tem forte papel nesse processo. Contudo, apesar da aceitação sistemática dessas normas e papéis de gênero, "é indispensável observar que, hoje, multiplicaram-se os modos de compreender, de dar sentido e de viver os gêneros" (LOURO, 2008, p. 18).

Não é novidade que os grupos que lutam por igualdade de gênero sofrem inúmeras repressões, são vítimas de ataques constantes de setores conservadores e vítimas de violência física, justamente por defenderem e buscarem espaço social e direitos iguais para todos e todas. Os movimentos sociais organizados compreenderam que era necessário "ocupar os espaços culturais como a mídia, o cinema, a televisão, os jornais, os currículos das escolas e universidades” (LOURO, 2008, p. 20) para alterar essa situação, pois a voz predominante nesses espaços sempre foi majoritariamente do homem branco heterossexual. E, por isso, passaram a ser verdades incontestáveis que a mulher era hierarquicamente o segundo sexo, incapaz de raciocínio lógico e de objetividade.

Resta-nos questionar: como ocorre, ainda hoje, a construção e legitimação desse discurso que inferioriza mulheres? A atribuição de diferentes papéis e status sociais aos gêneros, contribui para a consolidação desse discurso. Normalmente, ao aguardar o nascimento de um bebê, prepara-se um ambiente de acordo com o sexo. Geralmente, o azul é para os meninos e o rosa para as meninas. Os brinquedos oferecidos também são diferentes, sendo que aos meninos se entregam carrinhos, super-heróis, armas, jogos de montar, e às meninas, bonecas, panelinhas, fogõezinhos, fantasias de princesas e maquiagens. Deseja-se que desde cedo as crianças reproduzam os papéis sociais dos adultos. Muitos dos brinquedos dados às crianças já induzem a uma determinada profissão, que deverá ser exercida conforme o gênero.

Outro exemplo, é com relação a determinadas atitudes e comportamentos proibidos às meninas ou aos meninos. Com frequência se diz às meninas que certas 
atitudes que tiveram não são adequadas para uma menina: feche as pernas; sente direito. Aos meninos, afirma-se que homens não choram, transmitindo a noção de que devem reprimir seus sentimentos. E, se porventura, apresentarem algum comportamento tido como de mulher pela sociedade, são estereotipados e vítimas de deboches e outras agressões.

Tendemos a pensar que essas são coisas naturais. Justificamos que há poucas mulheres nas engenharias porque as mulheres são mais propensas à inteligência linguística, e que mais mulheres ocupam cargos ligados ao cuidado, como a enfermagem, a pedagogia, a psicologia, etc., em função de diferenças genéticas. Mas, como afirma Singer (2002, p. 43-45):

Os indícios de uma base biológica das diferenças de aptidão visual-espacial são um pouco mais complicados, mas consistem, em grande parte, em estudos genéticos que sugerem ser essa aptidão influenciada por um gene recessivo ligado ao sexo. Como resultado disso, estima-se que aproximadamente cinquenta por cento dos homens tenham uma vantagem genética em situações que exigem aptidão visual-espacial, mas essa mesma vantagem só é compartilhada por vinte e cinco por cento das mulheres. Os argumentos favoráveis e contrários a um fator biológico subjacente a maior capacidade verbal das mulheres e ao melhor raciocínio matemático dos homens são ainda frágeis demais para que se possa sugerir uma conclusão que os corrobore ou invalide. [...]. As diferenças de forças e fraquezas intelectuais dos sexos não podem explicar mais do que uma ínfima proporção da diferença de posições que homens e mulheres ocupam na nossa sociedade. Poderia explicar, por exemplo, por que existem mais homens que mulheres em profissões como a arquitetura e a engenharia, profissões que podem exigir aptidão visual-espacial; mas, mesmo nestas profissões, a magnitude das diferenças em termos numéricos não pode ser explicada pela teoria genética de aptidão visual-espacial. Esta teoria sugere que metade das mulheres são tão favorecidas geneticamente nesta área quanto os homens, o que explicaria a menor contagem média das mulheres nos testes de aptidão visual-espacial, mas não seria capaz de explicar o fato de que não há simplesmente duas vezes mais homens do que mulheres na arquitetura e engenharia - na verdade, há dez vezes mais, e em muitos países, esse número é ainda maior. Além do mais, se a aptidão visual-espacial superior explica o predomínio masculino na arquitetura e na engenharia, por que não se verifica uma vantagem feminina correspondente em profissões que exigem elevada capacidade de verbalização? [...]. Assim, mesmo se aceitarmos as explicações biológicas para a determinação dessas aptidões, podemos argumentar que as mulheres não têm as mesmas oportunidades que os homens para exercer em mais alto grau as aptidões que possuem.

As diferenças entre homens e mulheres são melhor explicadas por diferenças socioculturais, já que ao nascermos, imediatamente, se atribuem papéis a serem desempenhados para cada sexo.

Nascemos com um sexo biológico, e isso sim depende da biologia, mas assim que os pais descobrem que estão esperando um bebê, eles já começam a estabelecer papéis para essas crianças desempenharem em sociedade. Esses papéis são aquilo 
que define uma identidade masculina e outra feminina e são socialmente construídos, a isso denominamos gênero. Gênero são os comportamentos, as obrigações e o caráter que se exige que homens e mulheres possuam (GARCIA, 2015), cada qual com as características devidas, por terem nascido com determinado sexo. Gênero é diferente de sexo, visto que sexo são as diferenças entre os corpos, o órgão genital, o sistema reprodutor e os cromossomos, enquanto gênero são as normas e condutas determinadas para cada sexo. O que se espera de cada gênero é algo que pode variar dependendo da cultura, os papéis atribuídos a homens e mulheres não são universais.

Margareth Mead (2000) demonstrou isso em seus estudos de antropologia, ao observar a tribo Arapesh, notou que homem e mulher realizavam funções diferentes, mas ambos eram dóceis, não havendo distinções em relação ao comportamento. A maternidade não era uma obrigação feminina, mas uma relação compartilhada. Já na tribo Mundugomor, tanto o comportamento masculino quanto o feminino eram agressivos. Como eram as mulheres que cultivavam o fumo, em geral, elas não queriam engravidar para não ter que dividir sua posição de poder. Por outro lado, os homens desejavam ter filhas mulheres, porque assim teriam mais posses, pelo cultivo do fumo e ainda poderiam trocá-las por novas esposas.

$\mathrm{Na}$ tribo Tchambuli, os comportamentos femininos e masculinos eram distintos. A mulher detinha o poder, escolhia seu parceiro e controlava o lucro nas relações de comércio. Ainda que os homens fossem vistos como chefes da família, quem impunha as regras eram as esposas. Os homens eram responsáveis pelas atividades artísticas, atividades cerimoniais e ornamentos. Pode-se notar que o sexo biológico não determina os papéis ocupados na sociedade, uma vez que eles variam em diferentes culturas. O que impõe formas de comportamento é o gênero.

Considerando tais questões, relativas a distinção sexo/gênero, biológico/sociocultural, qual o papel dos espaços de educação formal para promoção da igualdade de gênero? A discriminação de gênero ocorre nos mais variados espaços, desde as construções familiares, religiosas, sociais, políticas e até mesmo em espaços escolares. Cabe à escola oportunizar espaços que promovam a busca por igualdade de gênero. Torna-se importante analisar o comportamento das professoras, professores e gestores escolares e promover cursos de formação continuada que os possibilitem desconstruir preconceitos. Faz-se necessário realizar cursos de formação, bem como analisar de maneira crítica as práticas pedagógicas que vêm sendo aplicadas, e pensa-las de modo a promover a igualdade de gênero. 
A construção desta igualdade exige que se evitem processos de discriminação no âmbito escolar. Apesar das polêmicas relacionadas aos estudos de gênero nas escolas, para promoção da igualdade, torna-se imprescindível que ações sejam praticadas desde os primeiros anos da vida escolar. A atuação do corpo técnico docente é fundamental para que a escola não se torne uma reprodutora de preconceitos e discriminações, e sim um espaço de construção de igualdades. Deste modo, vale analisar as posturas de meninos e meninas no ambiente escolar e as ações de professoras e professores voltadas para a discussão de gênero. $O$ debate de gênero, quando bem conduzido, pode auxiliar os estudantes em seu processo de construção de identidade.

Bell Hooks (2017) sugere que a superação do sexismo ${ }^{1}$ na prática pedagógica só é possível na medida que se adotam pedagogias anticolonialistas, críticas e feministas. É nessa interação complexa de múltiplas perspectivas que será possível transpor fronteiras e questionar os sistemas de dominação da supremacia branca capitalista e patriarcal em sala de aula. Defendemos que a partir de uma educação como prática da liberdade, proposta por Bell Hooks, juntamente com as reflexões apresentadas por Christine de Pizan, será possível superar as inequidades de gênero e promover uma educação que paute verdadeiramente o protagonismo humano.

Bell Hooks (2017) defende uma pedagogia engajada, e uma educação como prática da liberdade, que só é possível quando as professoras veem os estudantes como seres humanos integrais. A educação como prática da liberdade compreende a ligação entre as ideias aprendidas em contextos de educação formal e as ideias apreendidas pela prática da vida, e permite a partilha de conhecimentos. A educação como prática da liberdade representa a "ligação entre o que eles [os estudantes] estão aprendendo e sua experiência global da vida” (HOOKS, 2017, p. 33). Assim como Pizan (Cf. CALADO, 2006, p. 92), Bell Hooks considera a experiência, a leitura de mundo, como dimensão fundamental da aprendizagem.

Em uma sala de aula comprometida com a educação como prática da liberdade será mais necessário explicar a filosofia, a estratégia e a intenção do curso do que em uma sala da aula tradicional. Em muitos momentos, os estudantes podem se sentir incomodados, e não entender o valor de certo ponto de vista. $\mathrm{O}$ retorno de uma pedagogia engajada e de uma educação para igualdade de gênero não será imediato. A professora precisará abrir mão da necessidade de um reconhecimento imediato e compreender que cada estudante passa por um processo, e o reconhecimento de um aprendizado transformador pode vir muito tempo depois. Bell Hooks (2017, p. 60-61) nos ensina a praticar a compaixão: 
Não esqueço o dia em que um aluno entrou na aula e me disse: 'Nós fazemos seu curso. Aprendemos a olhar o mundo de um ponto de vista crítico, que leva em conta a raça, o sexo e a classe social. E não conseguimos mais curtir a vida.' Olhando para o resto da turma, vi alunos de todas as raças, etnias e preferências sexuais balançando a cabeça em sinal de assentimento. E vi pela primeira vez que pode haver, e geralmente há, uma certa dor envolvida no abandono das velhas formas de pensar e saber e no aprendizado de outras formas. Respeito essa dor. E agora, quando ensino, trato de reconhece-la, ou seja, ensino a mudança de paradigmas e falo sobre o desconforto que ela pode causar.

Descontruir-se, repensar-se, desestabilizar os próprios privilégios é doloroso. Rever os lugares sociais impostos a si e aos outros, abandonar preconceitos, reconhecê-los nos outros, questioná-los, são processos complexos. Os novos modos de conhecer, propostos por uma educação como prática da liberdade, criam novos modos de ser, tanto para professoras quanto para estudantes. Esses novos modos de conhecer e de ser se voltam para a igualdade de gênero e para o protagonismo de todas/os envolvidos.

Questionarmos nossas ideias e questionarmos nossos hábitos, aliando teoria e prática, como nos exige essa proposta não é fácil, não é simples, não é rápido, mas é o único modo de transformar a realidade, tornando-a mais justa para todos e todas e possibilitando uma educação para o protagonismo.

\section{Conclusão}

O trabalho em questão se propôs a investigar os principais pontos defendidos por Christine de Pizan em prol de uma educação igualitária, além de analisar sua importância para o protagonismo humano. Dividido em duas etapas, no primeiro momento discorreu sobre a biografia de Pizan e o contexto em que a autora estava inserida. Pode-se observar que, distintamente da visão popular da Idade Média, como a idade das trevas, o ambiente no qual Pizan se situava demonstra uma abertura para o papel protagonista da mulher, comprovado pelas atribuições que Christine foi adquirindo no decorrer dos fatos históricos, com destaque ao seu papel de escritora.

A importância de uma educação de qualidade, bem como o incentivo à leitura, pode ser percebida na formação de Christine, que possuía acesso à biblioteca real, um ambiente fértil na busca do saber. Tal questão contribuiu para um pensamento além de seu tempo, que lhe possibilitou desenvolver uma percepção da mulher como ser dotado dos mesmos direitos que o homem.

Em um segundo momento, o foco do trabalho voltou-se para compreensão de como Christine dialogava com a educação. Diante do exposto, pode-se evidenciar que os principais pontos defendidos no estudo apresentado foram a educação igualitária e o potencial protagonista da mulher quando detentora do conhecimento. 
Esses tópicos se fundamentaram na forma como ela utilizou a literatura, trabalhando com problemáticas reais e cenários ideais. Pizan via na educação a possibilidade de promover a igualdade entre os gêneros, bem como de inverter o papel passivo da mulher, tornando-a protagonista.

Pizan demonstrou que muito além de questões biológicas, a definição da posição humana inserida em uma sociedade é fundamentada pela educação. Além disso, importantes questões em prol do desenvolvimento humano e equilíbrio no contexto social foram apresentadas, como por exemplo, a ênfase em reconhecer a inexistência de um saber absoluto. Tal percepção tem potencial de impulsionar o pensamento distinto das verdades concretas impostas na época (e inclusive nos dias atuais), além de flexibilizar os dogmas vistos como imutáveis.

No contexto atual, percebemos que a luta iniciada por Pizan, considerada por muitas como a primeira feminista por reivindicar educação igualitária para meninos e meninas e questionar produções literárias misóginas, mantém-se ativa. As teóricas feministas, em pleno século XXI, ainda discutem os reflexos de um processo de socialização que limita o desenvolvimento das meninas, enquanto estimula o dos meninos. Por mais que tenhamos evoluído em alguns pontos, ainda há forte resistência frente ao debate de gênero nas escolas e à defesa de uma educação igualitária.

Teóricas como Bell Hooks (2017) têm se dedicado a pensar uma prática pedagógica que dê conta de produzir uma educação libertadora, que possibilite o protagonismo de todas/os as/os estudantes. Essa autora considera que a leitura de mundo e as experiências dos estudantes devem ser consideradas no processo de aprendizagem, do mesmo modo que Pizan já defendia na Idade Média.

Diante da compreensão da importância da educação para o protagonismo humano, cujo movimento de educar com iguais condições ambos os gêneros propicia equidade social, salienta-se a relevância de se alcançar os objetivos número 4 e 5 (ONU, 2015), que preconizam: "assegurar a educação inclusiva e equitativa de qualidade, e promover oportunidades de aprendizagem ao longo da vida para todos" e "alcançar a igualdade de gênero e empoderar todas as mulheres e meninas".

\section{Notas}

1 Bell Hooks, enquanto teórica negra, analisa a realidade a partir de uma estrutura interseccional, desse modo considera que nossa sociedade é um heterocapitalismo patriarcal de supremacia branca. As opressões que vivenciamos não devem ser consideradas separadamente, mas como intersecções. Considera que a superação do sexismo, do racismo e dos preconceitos de classe devem ser pensados conjuntamente. 


\section{Referências}

ALVES, B. M.; PITANGUY, J. O que é o feminismo? São Paulo: Brasiliense, 2017.

BEAUVOIR, S. O segundo sexo. Tradução de Sérgio Milliet. 2. ed. Rio de Janeiro: Nova Fronteira, 2009.

CALADO, L. E. F. A Cidade das Damas a construção da memória feminina no imaginário utópico de Christine de Pizan. Tese (Doutorado em Teoria da Literatura) - Programa de Pós-Graduação em Letras, Universidade Federal do Pernambuco, Recife, 2006.

CARDOSO, L. L. Entre mulheres e damas: resistência tardo-medieval em Christine de Pizan. Revista Diálogos Acadêmicos, Fortaleza, v. 6, n. 2, p. 130-144, 2017.

GARCIA, C. C. Breve história do feminismo. 3. ed. São Paulo: Claridade, 2015.

HOOKS, Bell. Ensinando a transgredir: a educação como prática da liberdade. São Paulo: WMF Martins Fontes, 2017.

KARAWEJCZYK, M. Christine de Pisan, uma feminista no medievo?! Historiæ, Rio Grande, n. 8, p. 189-203, 2017.

LEITE, L. Christine de Pizan: uma resistência na aprendizagem da moral de resignação. Tese (Doutorado em Língua e Literatura Francesa) - Programa de Pós-Graduação em Língua e Literatura Francesa e Estudos Medievais, Universidade de São Paulo, São Paulo, 2008.

LEITE, L. Christine de Pizan e o seu projeto utópico. Revista MORUS - Utopia e Renascimento, n. 13, p. 113-120, 2018. Disponível em: http://revistamorus.com.br/index.php/morus/article/ view/340/0. Acesso em: 17 jan. 2020.

LLOYD, G. The Man of Reason. Minneapolis: University of Minnesota Press, 1984.

LLOYD, E. Objectivity and Double Standart of Feminist Epistemologists. Synthese, n. 104, p. 351-381, set./1995.

LONGINO, H. Epistemologia feminista. In: GRECO, J.; SOSA, E. Compêndio de Epistemologia. Tradutores Alessandra Siedschlag, Fernandes e Rogério Bettoni. São Paulo: Loyola, 2012. p. 505-546.

LOURO, Guacira Lopes. Gênero e sexualidade: pedagogias contemporâneas. Pro-Posições, v. 19, n. 2, p. 17-23, maio/ago. 2008. Disponível em: http://www.scielo.br/pdf/pp/v19n2/a03v19n2. pdf. Acesso em: 20 dez. 2017.

MEAD, M. Sexo e temperamento. Trad. Rosa Krausz. 4. ed. São Paulo: Perspectiva, 2000.

ONU. 17 objetivos do desenvolvimento sustentável. 2015. Disponível em: https://nacoesunidas. org/conheca-os-novos-17-objetivos-de-desenvolvimento-sustentavel-da-onu/. Acesso em: 25 out. 2019.

ROONEY, P. Gendered reason: sex metaphor and conceptions of reason. Hypatia, Cambridge, v. 6, n. 2 , p. $77-193,1991$. 
SILVA, D. E. O alegórico e as vozes antimisóginas como estratégia narrativa em Christine de Pizan: a cidade das damas. 2016. Dissertação (Mestrado em Letras) - Programa de Pós-Graduação em Letras, Universidade Federal da Paraíba, João Pessoa, 2016.

SINGER, Peter. Ética prática. São Paulo: Martins Fontes, 2002.

VIANNA, C.; FINCO, D. Meninas e meninos na educação infantil: uma questão de gênero e poder. Cadernos Pagu, Campinas, n. 33, p. 265-283, jul./dez. 2009. 